University of South Florida

DIGITAL COMMONS

Digital Commons @ University of

@ UNIVERSITY OF SOUTH FLORIDA

South Florida

$5-1987$

\title{
Velocity and Temperature Observations during the Seasonal Response of the Equatorial Atlantic Experiment at $0^{\circ}, 28^{\circ} \mathrm{W}$
}

\author{
Robert H. Weisberg \\ University of South Florida, weisberg@marine.usf.edu \\ J. H. Hickman \\ University of South Florida \\ T. Y. Tang \\ University of South Florida \\ T. J. Weingartner \\ University of South Florida
}

Follow this and additional works at: https://digitalcommons.usf.edu/msc_facpub

\section{Scholar Commons Citation}

Weisberg, Robert H.; Hickman, J. H.; Tang, T. Y.; and Weingartner, T. J., "Velocity and Temperature Observations during the Seasonal Response of the Equatorial Atlantic Experiment at $0^{\circ}, 2^{\circ} \mathrm{W}^{\prime \prime}$ (1987). Marine Science Faculty Publications. 393.

https://digitalcommons.usf.edu/msc_facpub/393

This Article is brought to you for free and open access by the College of Marine Science at Digital Commons @ University of South Florida. It has been accepted for inclusion in Marine Science Faculty Publications by an authorized administrator of Digital Commons @ University of South Florida. For more information, please contact digitalcommons@usf.edu. 


\title{
Velocity and Temperature Observations During the Seasonal Response of the Equatorial Atlantic Experiment at $0^{\circ}, 28^{\circ} \mathrm{W}$
}

\author{
R. H. Weisberg, J. H. Hickman, T. Y. TANG, and T. J. Weingartner \\ Department of Marine Science, University of South Florida, Saint Petersburg
}

\begin{abstract}
Continuous 2.7-year time series of upper ocean currents and temperature at $0^{\circ}, 28^{\circ} \mathrm{W}$ collected during the Seasonal Response of the Equatorial Atlantic Experiment are presented. The thermocline underwent distinctive annual cycles in response to forcing by the surface wind stress, and the core of the Equatorial Undercurrent tracked the thermocline. While the vertical position of the thermocline and the undercurrent appear to be simply related, the transport of the undercurrent did not show a replicating annual cycle, and the speed at the undercurrent core remained relatively constant. Near surface flow when averaged over the 2.7 years was not statistically different from zero, and a westward flowing South Equatorial Current was rarely established despite strong easterly wind stress in all 3 years. Crossequatorial flow was also zero in the mean at this location.
\end{abstract}

\section{INTRODUCTION}

The Seasonal Response of the Equatorial Atlantic (SEQUAL) experiment and the Programme Français Océan et Climat dans l'Atlantique Equatorial (FOCAL) were designed to provide a basinwide and synoptic set of measurements for studying the annual variations in the upper ocean currents and temperature of this region. The present paper describes the data collected on the equator at $28^{\circ} \mathrm{W}$ using surface moored current meters. This location provided continuous time series from February 1983 to October 1985. Sections 2 and 3 will present the data and discuss the evolution of the annual variations in the velocity components and temperature over the upper $200 \mathrm{~m}$ which includes the surface South Equatorial Current (SEC) and the subsurface Equatorial Undercurrent (EUC) embedded within the thermocline. Three replicates of the thermocline's evolution through its annual cycle are shown. These differ individually from climatology in transition from weak to strong (and conversely) wind seasons owing to the rapidly varying nature of the wind stress. While the vertical position of the EUC changes with the thermocline and hence undergoes a distinctive annual cycle, variations in transport do not, and the speed at the core remains relatively steady throughout the year. Westward flow at the surface was intermittent and rarely penetrated to $50-\mathrm{m}$ depth. When the SEC did establish upon onset of increased easterly wind stress it only remained as such for $2-3$ months even though strong easterlies persisted much longer. During 1983, when the easterlies were the strongest of the 3 years sampled, the SEC directly on the equator was the weakest. The north component of velocity was zero in the mean and exhibited short duration wave packets centered upon a 25-day period and modulated on an annual cycle. Section 4 gives an empirical orthogonal function analysis over the upper $200 \mathrm{~m}$. The east component of velocity has a more complicated vertical structure than does either the north component or temperature, with much of the transport variability due to the near-surface current fluctuations. Section 5 is a preliminary look at higherfrequency variability averaged over the full record. Section 6

Copyright 1987 by the American Geophysical Union.

Paper number $7 \mathrm{C} 0177$.

0148-0227/87/007C-0177\$05.00 discusses the EUC relative to previous findings, and section 7 provides a summary.

\section{Measurements}

The data were collected using vector-averaging current meters (VACMs) manufactured by EG\&G Sea Links Systems, Inc., suspended from taut wire surface moorings. Halpern [1987] describes the mooring system as used in an equatorial Pacific Ocean application under similar conditions and gives results from a current meter intercomparison study between VACMs and vector-measuring current meters (VMCMs, also manufactured by EG\&G Sea Links Systems, Inc.) shackled together at $1-\mathrm{m}$ separations at $15 \mathrm{~m}, 100 \mathrm{~m}, 120 \mathrm{~m}$, and $160 \mathrm{~m}$. Because the VMCM's sensors are more responsive to highfrequency water motions, it is considered to be more accurate than a VACM [Weller and Davis, 1980]. Qualitatively, results from the two instruments were indistinguishable. Excellent coherence was found between each VACM-VMCM doublet's data. Quantitatively, the 6-month mean speeds recorded by the VACMs were $5 \%-12 \%$ higher than those of the VMCMs, with the largest difference occurring at $15-\mathrm{m}$ depth. At and below $100 \mathrm{~m}$, the rms amplitude difference within a decadal frequency range was less than $1 \mathrm{~cm} / \mathrm{s}$, and a kinetic energy mismatch at the $95 \%$ confidence interval was limited to frequencies higher than $1.8 \mathrm{cph}$. With laboratory tests showing that VACMs and VMCMs tend to overestimate and underestimate speeds in the presence of oscillatory currents, respectively, it was concluded that VACMs are as acceptable as VMCMs on equatorial surface moorings of this type, and previous mooring intercomparisons have shown the suitability of VMCMs from surface moorings for upper ocean measurements under much more severe environmental conditions [Halpern et al., 1981].

Table 1 lists the launch and recovery information for the five successive deployments that comprised a total sampling duration of 2.7 years. The individual deployment sites were all within $5 \mathrm{~km}$ of the mean position at $00^{\circ} 03^{\prime} \mathrm{N}, 28^{\circ} 10^{\prime} \mathrm{W}$ with a water depth of $4120 \mathrm{~m}$. The instruments were deployed at depths ranging from $10 \mathrm{~m}$ to $300 \mathrm{~m}$, with a sampling interval of 15 minutes. After editing, the vector-averaged north and east velocity components and temperature were further averaged to hourly values with a start time of 1900 UT on 
a. TEMPERATURE

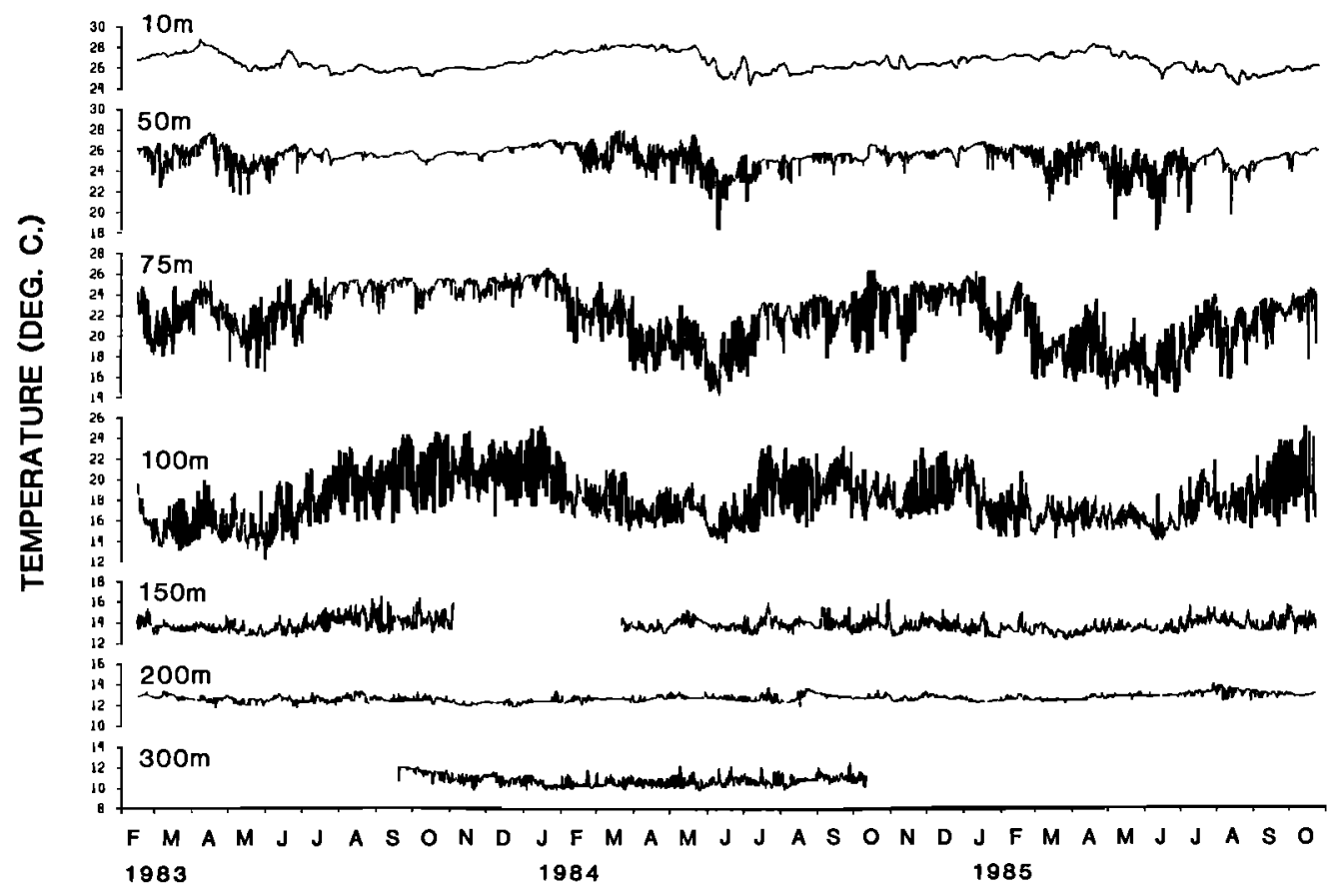

b. EAST COMPONENT

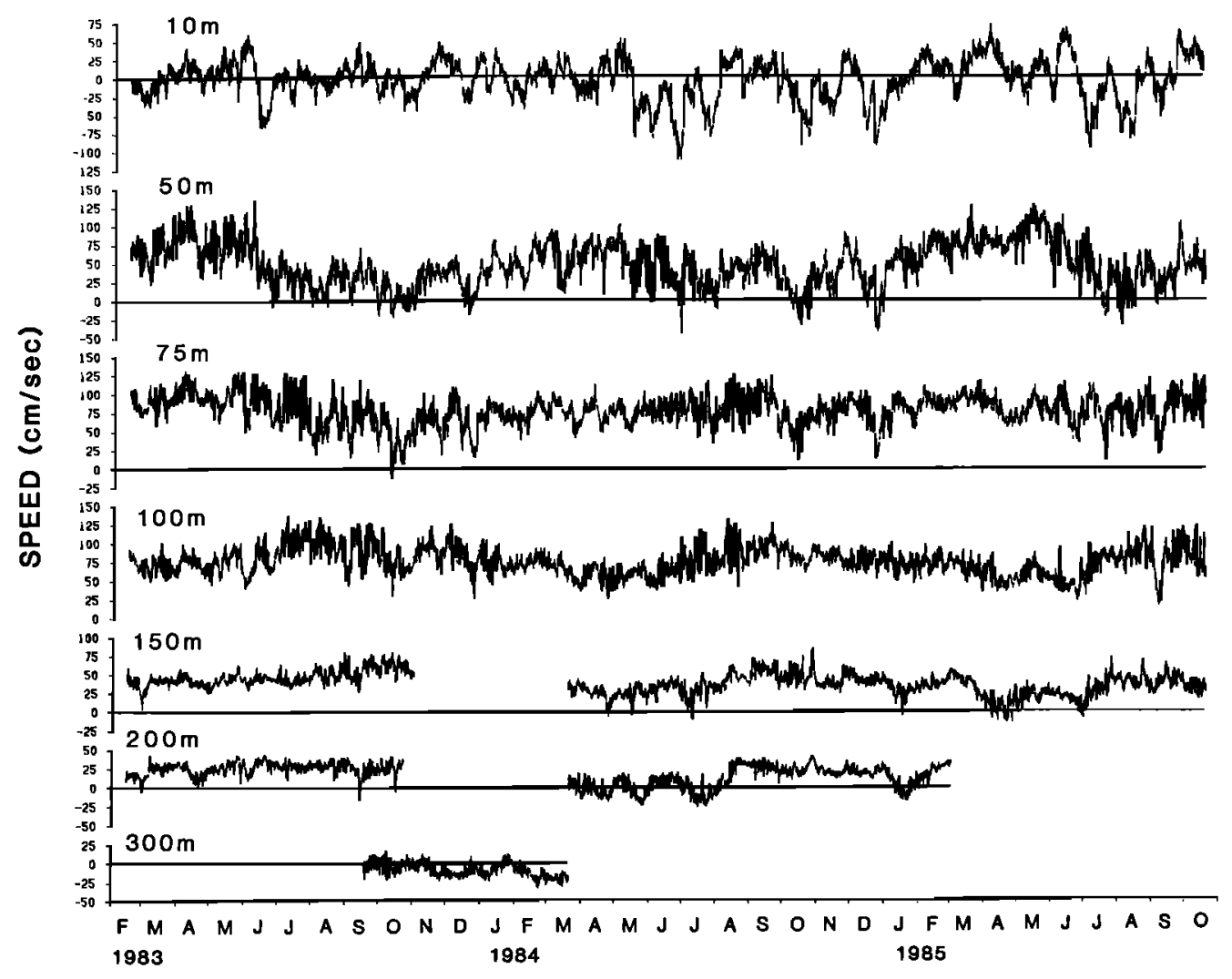

Fig. 1. Hourly averaged temperature and velocity component time series sampled on the equator at $28^{\circ} \mathrm{W}$ from February 1983 to October 1985: (a) temperature, (b) east component, and (c) north component.

February 13, 1983, and a record length of 23,563 hours. Record gaps between deployments which are generally less than 1 day were filled by linear interpolation. All of the deployments had instruments down to $200 \mathrm{~m}$, and two of them also had instruments at the $300-\mathrm{m}$ level. Of these two, only one yielded data, so for uniformity, discussion will focus upon the upper $200 \mathrm{~m}$ of the water column, where the data returns were generally very good $(94 \%)$. 


\section{c. NORTH COMPONENT}

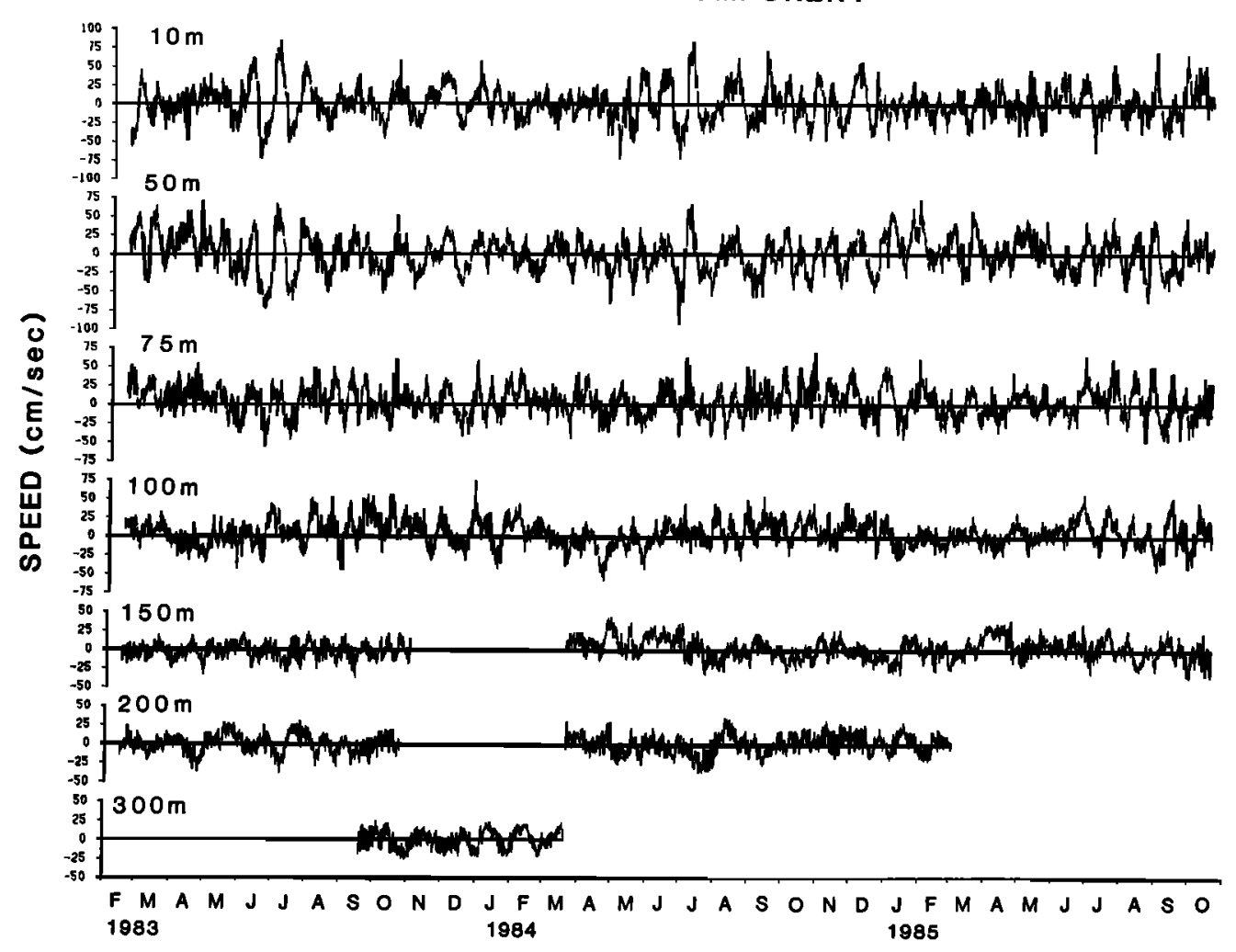

Fig. 1. (continued)

TABLE 1. Launch and Recovery Information for the Five Deployments During the 2.7 Years of Current Meter Data From the Equator at $28^{\circ} \mathrm{W}$.

\begin{tabular}{|c|c|c|c|c|c|}
\hline Buoy & Location & $\begin{array}{l}\text { Depth, } \\
\text { m }\end{array}$ & $\begin{array}{c}\text { Set } \\
\text { Time/Date }\end{array}$ & $\begin{array}{l}\text { Recovered } \\
\text { Time/Date }\end{array}$ & Instrument Depths, m \\
\hline $\mathrm{SA} 2 *$ & $0^{\circ} 00.2^{\prime} \mathrm{S}, 28^{\circ} 08.8^{\prime} \mathrm{W}$ & 4117 & 1623 UT, Feb. 13, 1983 & 2200 UT, Sept. 16, 1983 & $10,50,75,100,150,200$ \\
\hline SB2 & $0^{\circ} 03.5^{\prime} \mathrm{N}, 28^{\circ} 09.3^{\prime} \mathrm{W}$ & 4090 & 1053 UT, Sept. 18,1984 & 1959 UT, March 20, 1984 & $10,50,75,100,150, \uparrow 200, \ddagger 300$ \\
\hline $\mathrm{SC} 2$ & $0^{\circ} 03.3^{\prime} \mathrm{N}, 28^{\circ} 10.6^{\prime} \mathrm{W}$ & 4120 & 0928 UT, March 21, 1984 & 1342 UT, Oct. 11, 1984 & $10,50,75,100,150,200,3008$ \\
\hline SD2 & $0^{\circ} 03.4^{\prime} \mathrm{N}, 28^{\circ} 11.8^{\prime} \mathrm{W}$ & 4123 & 0411 UT, Oct. 12,1984 & 1819 UT, March 3, 1985 & $10,50,75,100,150,200$ \\
\hline SE2 & $0^{\circ} 05.3^{\prime} \mathrm{N}, 28^{\circ} 08.6^{\prime} \mathrm{W}$ & 4118 & 0441 UT, March 4, 1985 & 1328 UT, Oct. 22,1985 & $10,50,75,100,150,200 \S$ \\
\hline
\end{tabular}

Mean location, $0^{\circ} 03^{\prime} \mathrm{N}, 28^{\circ} 10^{\prime} \mathrm{W}$.

"Mooring adrift for 1 day prior to recovery.

†Electronic failure, November 3, 1984.

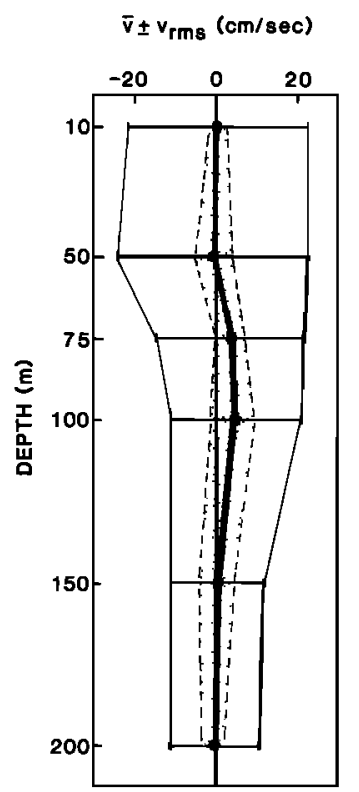

$¥$ Rotor failure, October 24, 1984.

$\S$ Vane failure over entire record.
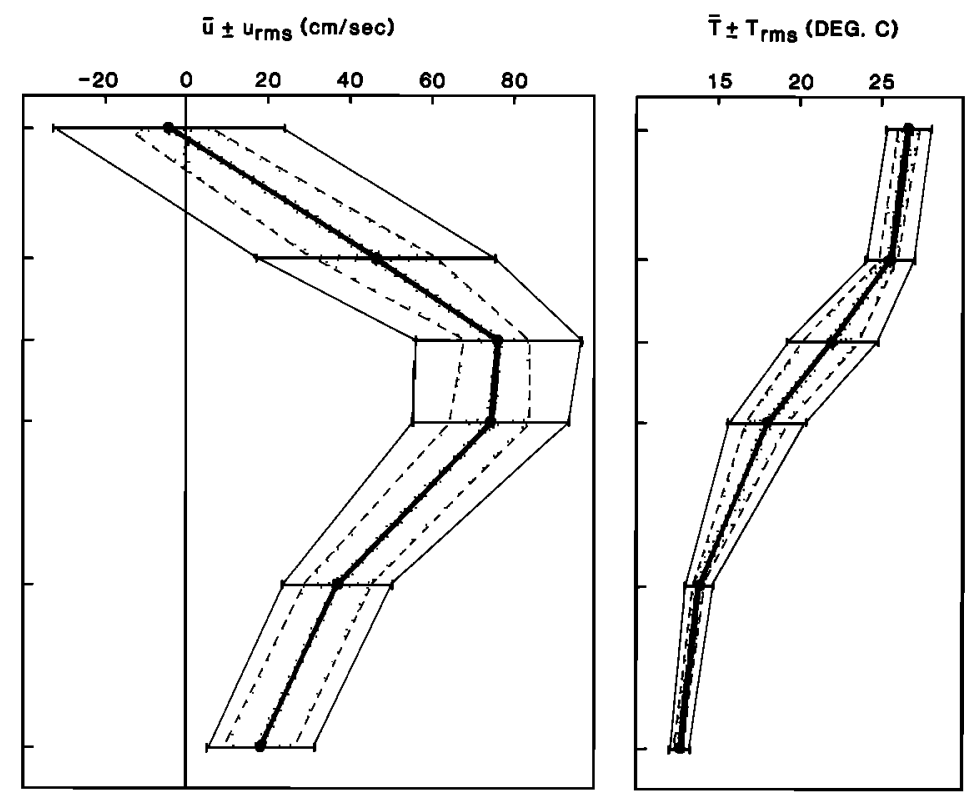

Fig. 2. Mean values, rms deviations, and $90 \%$ confidence (stippled) intervals for the means as a function of depth computed from velocity component and temperature time series collected over 27 years on the equator at $28^{\circ} \mathrm{W}$. 
TABLE 2. Means, Root Mean Square Deviations, and $90 \%$ Confidence Intervals for the Means Calculated Over the 2.7 Years of Data for the $u$ and $v$ Velocity Components and Temperature From the Equator at $28^{\circ} \mathrm{W}$

\begin{tabular}{rrrrrrrrrr}
\hline $\begin{array}{c}\text { Depth, } \\
\mathrm{m}\end{array}$ & $\bar{u}$ & $\begin{array}{c}u_{\text {rms, }} \\
\mathrm{cm} / \mathrm{s}\end{array}$ & \multicolumn{1}{c}{$\boldsymbol{e}_{\mathrm{u}}$} & \multicolumn{1}{c}{$\bar{v}$} & $\begin{array}{l}v_{\text {rms }} \\
\mathrm{cm} / \mathrm{s}\end{array}$ & $e_{v}$ & $\bar{T}$ & $\begin{array}{c}T_{\text {rmss }} \\
\mathrm{C} \mathrm{C}\end{array}$ & $e_{T}$ \\
\hline 10 & -4.7 & 28.1 & \pm 9.9 & 0.3 & 22.3 & \pm 2.0 & 26.7 & 1.3 & \pm 0.6 \\
50 & 46.1 & 29.0 & \pm 15.3 & -0.6 & 23.3 & \pm 4.4 & 25.5 & 1.5 & \pm 0.5 \\
75 & 76.3 & 20.7 & \pm 7.9 & 3.9 & 18.2 & \pm 3.2 & 22.0 & 2.8 & \pm 1.8 \\
100 & 74.5 & 19.0 & \pm 9.7 & 4.5 & 16.2 & \pm 5.0 & 18.1 & 2.4 & \pm 1.3 \\
150 & 37.3 & 13.6 & \pm 8.3 & 0.7 & 11.6 & \pm 4.3 & 14.0 & 0.8 & \pm 0.3 \\
200 & 18.1 & 13.7 & \pm 8.5 & -0.4 & 11.0 & \pm 2.4 & 12.8 & 0.6 & \pm 0.2 \\
\hline
\end{tabular}

Hourly averaged north and east velocity components and temperature time series are shown in Figure 1. Low-frequency oscillations (several-day and longer time scales) with distinct horizontal anisotropy and vertical inhomogeneity generally characterize these data. Measurable tidal and higher frequency oscillations are also present. Figure 2 and Table 2 give the mean values, the root-mean-squared (rms) deviations about these means, and the $90 \%$ confidence intervals for the mean value estimates. The confidence intervals are based upon a Student's $t$ distribution for the sample mean of a Gaussian distributed random variable with unknown variance. The variance of the mean estimate was obtained from the spectral estimate at zero frequency as described by Papoulis [1965] and as employed for example by Weisberg and Horigan [1981]. This procedure is meaningful as long as the spectrum of the time dependent variations levels off or preferably decreases at the low-frequency end (see Figure 3); i.e., the longest time scales of variability are reasonably well sampled, since it is this portion of the spectrum that causes the sample mean to vary.

The mean currents are highly anisotropic. There is no significant mean flow in the north-south direction over the upper $200 \mathrm{~m}$ in sharp contrast to the well-defined EUC with mean flow to the east in the thermocline and maximum speed between $50 \mathrm{~m}$ and $150 \mathrm{~m}$. The current fluctuations are also anisotropic in accordance with quasi-geostrophic dynamics in the equatorial region [e.g., Cane and Sarachik, 1976]. This is apparent from the variance density spectra for the velocity components and the temperature time series shown in the three panels of Figure 3. Each panel superimposes the spectra from $10-\mathrm{m}, 100-\mathrm{m}$, and $200-\mathrm{m}$ depths offset by 1 decade along with the $90 \%$ confidence interval for random errors. The spectra were calculated from demeaned, $10 \%$ cosine-tapered, and zero-augmented time series using a fast Fourier transform (over an augmented record length of 24,000 hours) and variable frequency domain smoothing. Smoothing was performed by convolving a uniform spectral window, 11 fundamental frequency bands in width, across the periodogram to beyond the $M_{2}$ tidal line. The window width was then increased to 41 fundamental bands, and independent block averages were calculated between there and the Nyquist frequency of $2 \mathrm{cph}$. The north and east velocity component spectra differ at the lowfrequency end in that the north component spectra peak at time scales of around 1 month and then decrease at lower frequency, while the east component spectra do not exhibit such a peak. This low-frequency separation has been pre-

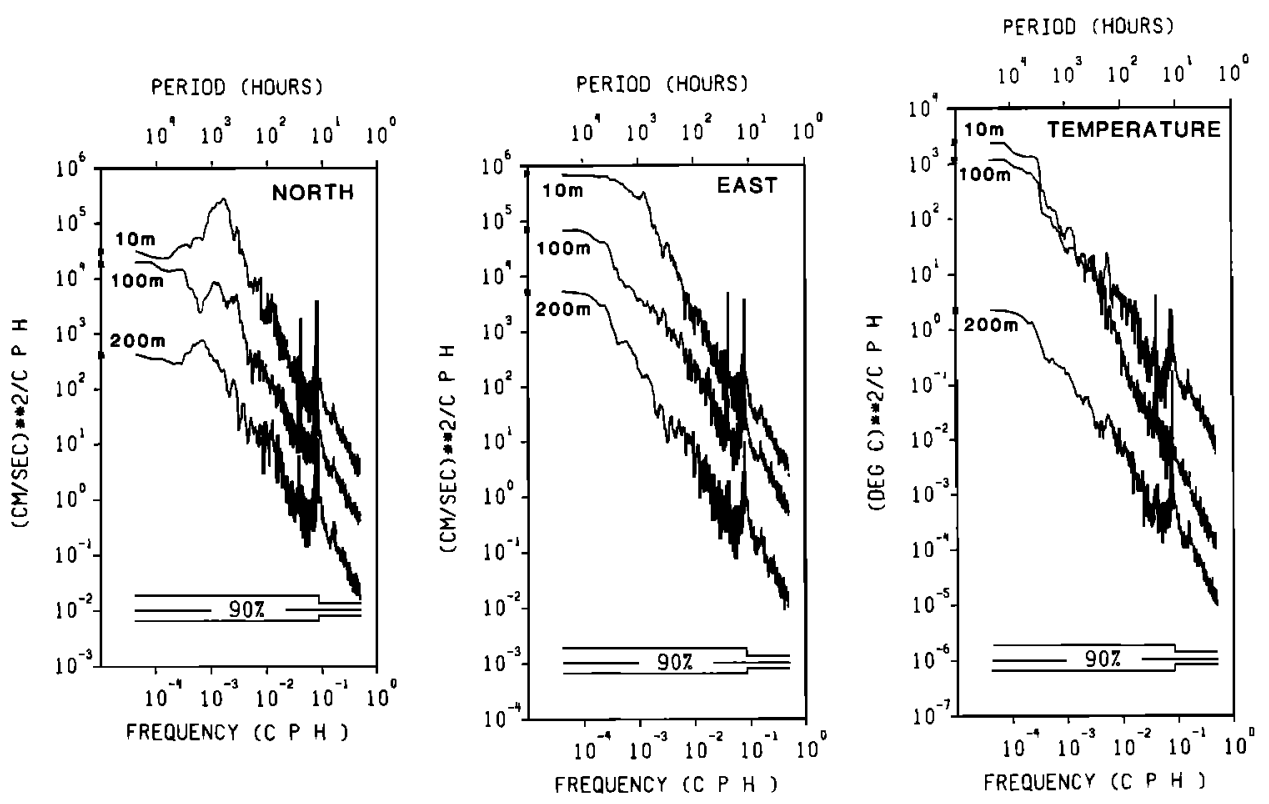

Fig. 3. Variance density spectra as a function of frequency for velocity component and temperature fluctuations at depths of $10 \mathrm{~m}, 100 \mathrm{~m}$, and $200 \mathrm{~m}$. The units on the ordinate correspond to the spectra at $10-\mathrm{m}$ depth. Spectra from $100 \mathrm{~m}$ and $200 \mathrm{~m}$ are displaced downward by 1 decade each, and $90 \%$ confidence intervals for random errors are as given. 
NORTH

PERIOD (HOURS)
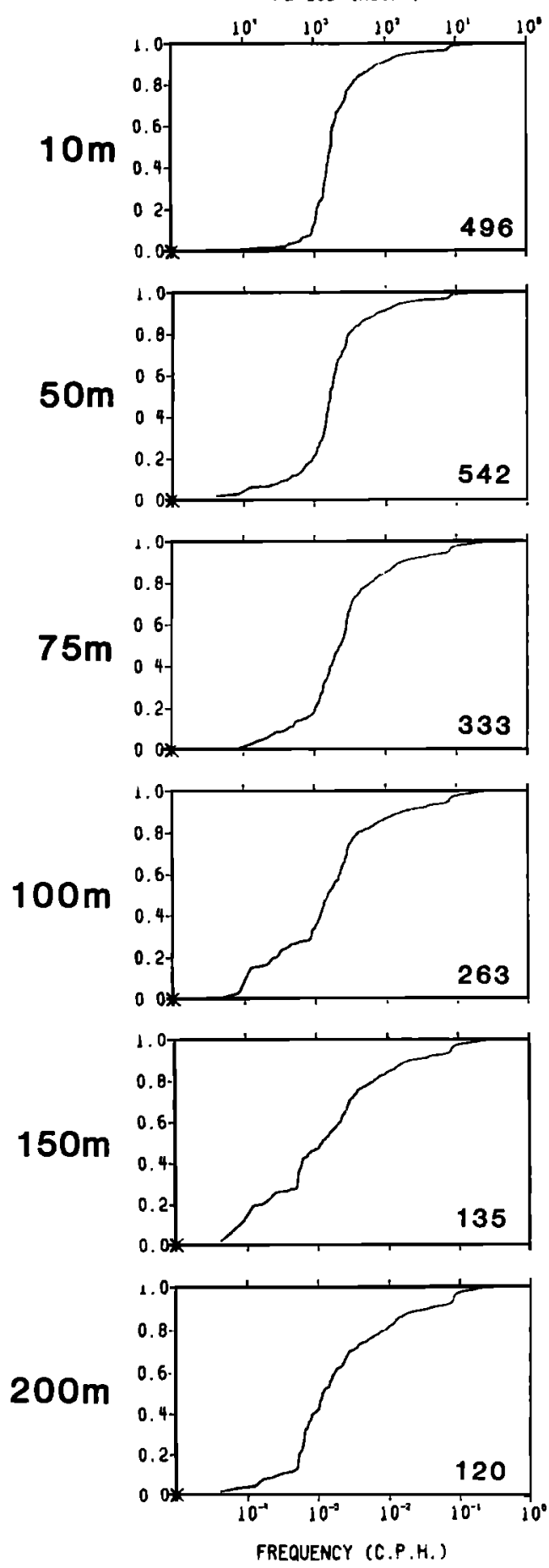

EAST

PERIOD (HOURS)
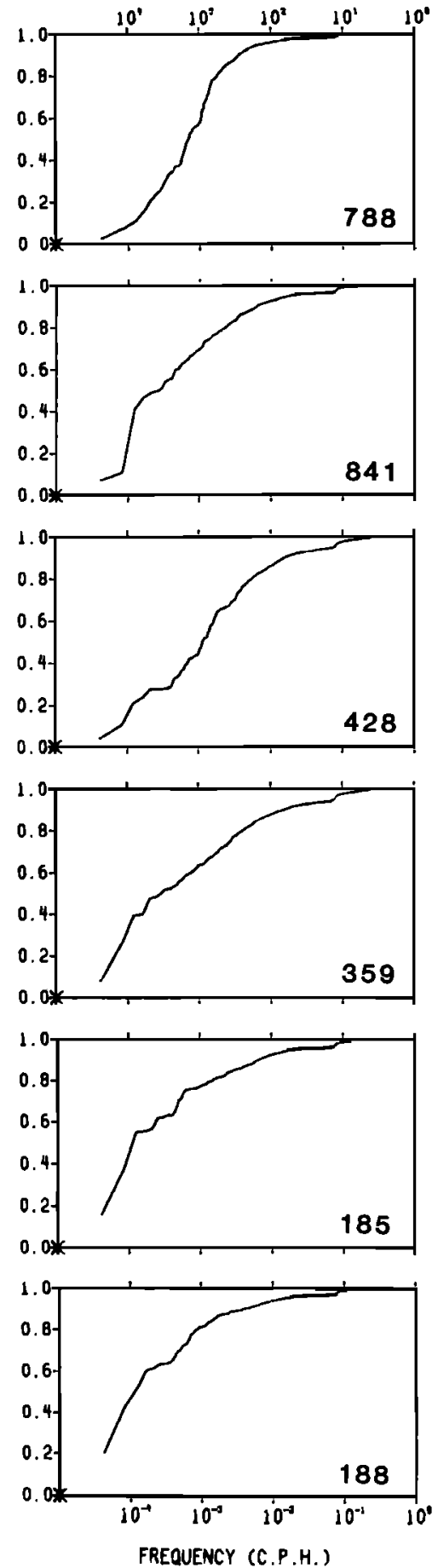

TEMPERATURE

PERTOD (HOURS)
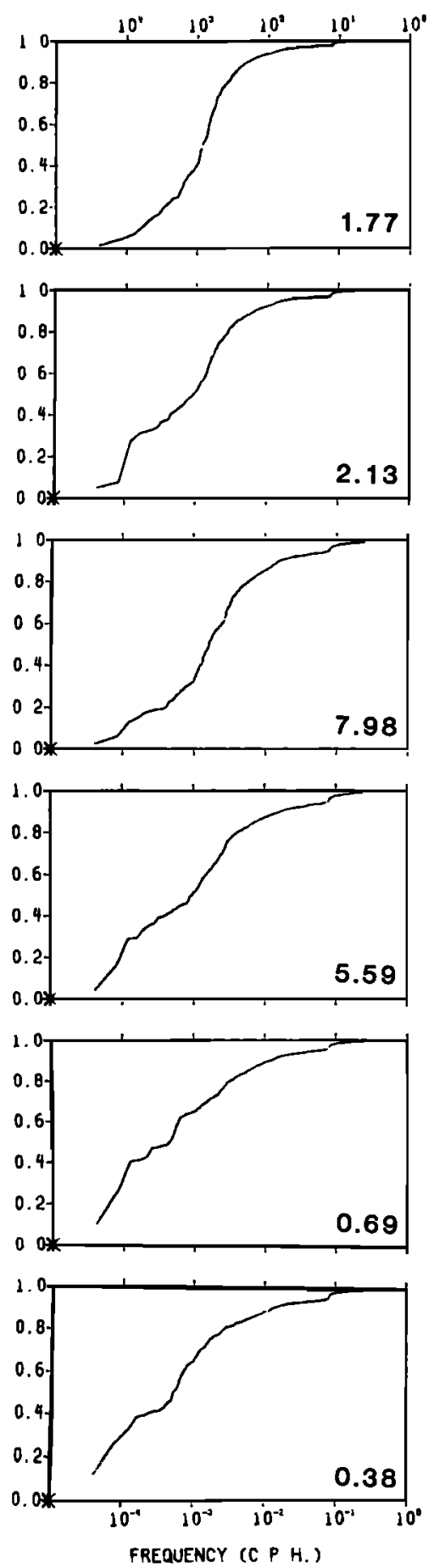

Fig. 4. Variance distribution as a function of frequency for velocity component temperature fluctuations at all six depths sampled. The ordinate gives the fraction of total variance contained at frequencies below a chosen value. Total variance is given in the lower right-hand corner of each plate. Variance contained in any frequency band may be obtained from the fraction in that band times the total.

viously reported for equatorial Atlantic and Pacific Ocean data by Weisherg and Horigan [1981] and Philander et al. [1985] respectively. The north and east velocity component spectra begin to coalesce at time scales shorter than a month, and this will be discussed in a later section. The fractional variances in any given frequency band for the velocity components and temperature at all of the six depths between $10 \mathrm{~m}$ and $200 \mathrm{~m}$ are given in Figure 4 along with the total vari- 

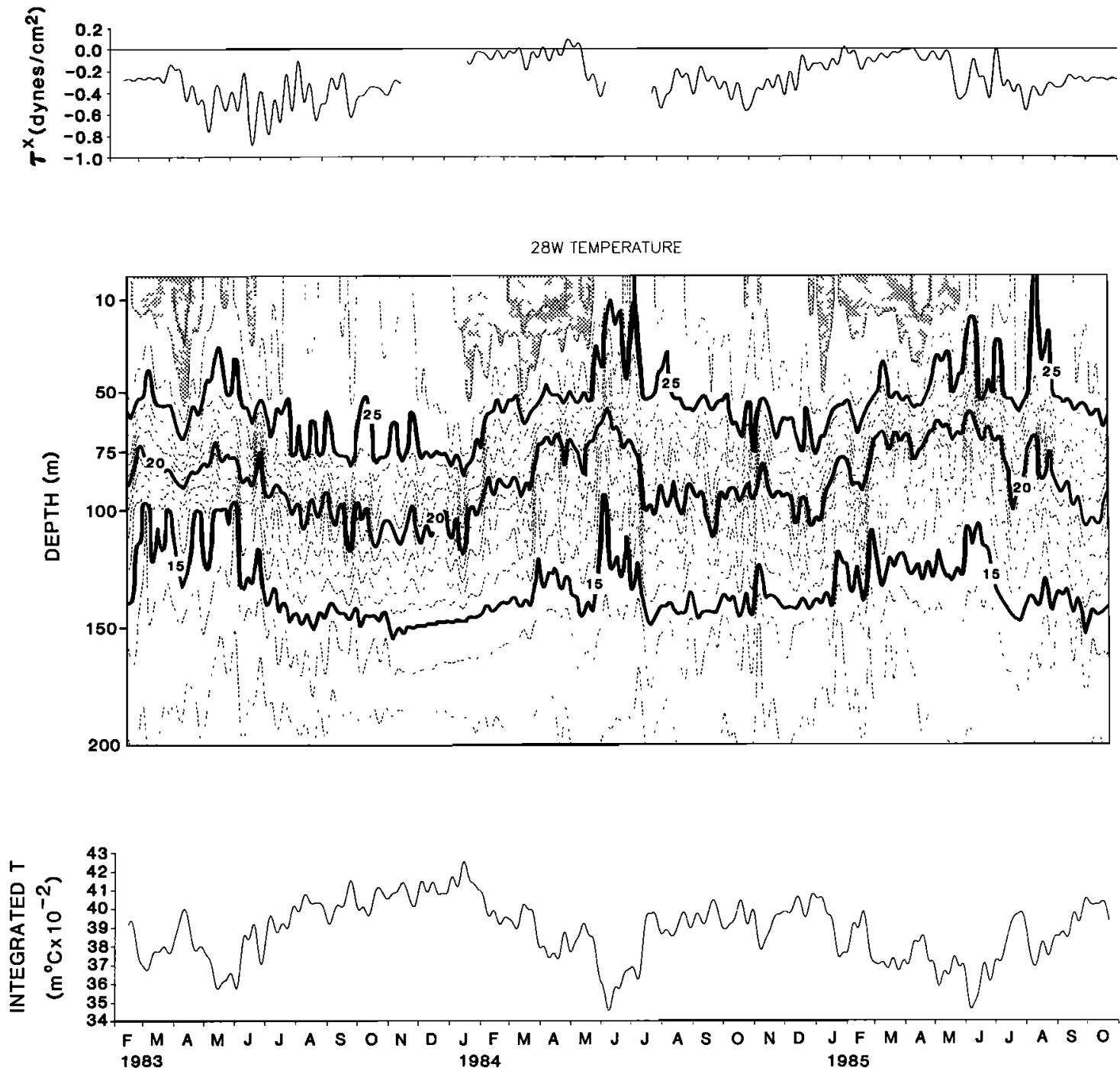

Fig. $5 a$

Fig. 5. Isotherm or isotach depths and vertically integrated temperature or volume transport per unit width as a function of time computed using temperature and velocity component time series low-pass filtered to exclude fluctuations at time scales shorter than 10 days. (a) Temperature with a contour interval of $1^{\circ} \mathrm{C}$ along with a similarly low pass-filtered zonal wind stress component time series from SPP courtesy of S. Garzoli (temperatures above $27^{\circ} \mathrm{C}$ are highlighted by stippling). (b) East component with a contour interval of $20 \mathrm{~cm} / \mathrm{s}$ (regions of westward flow are stippled). (c) North component, with a contour interval of $20 \mathrm{~cm} / \mathrm{s}$ (solid lines denote the zero contour, short-dashed lines denote southward flow, and long-dashed lines denote northward flow).

ances. The partition of variance amongst different trequency bands is thus obtainable.

\section{AnNual Cycle}

Inspection of Figure 1 shows distinctive patterns in the temperature and the east velocity component that repeat annually. The north velocity component varies at higher frequency, but these variations appear to be modulated annually. To view these annual variations over the upper $200 \mathrm{~m}$ more clearly, the time series were first low-pass filtered to exclude oscillations at time scales shorter than 10 days using a truncated Fourier transform and then contour plotted. Figures $5 a, 5 b$, and $5 c$ show the resulting isotherm or isotach depths as func- tions of time along with the vertically integrated temperature or volume transport over the upper $200 \mathrm{~m}$ where the surface values have been set equal to the values at $10 \mathrm{~m}$. Also included in Figure $5 a$ is a similarly low pass-filtered time series of easterly surface wind stress as measured at Saint Peter and Paul Rocks (SPP) and provided by S. Garzoli (personal communication, 1986).

Analytical studies have shown that it is essentially the zonal integral of easterly wind stress along the equator that effects the annual cycle in the upper equatorial ocean velocity and temperature fields [e.g., Moore and Philander, 1977; Cane and Sarachik, 1977]. Currents are generated which redistribute mass, and together with equatorial long waves emanating from the boundaries, these provide the mechanisms by which 
28W EAST
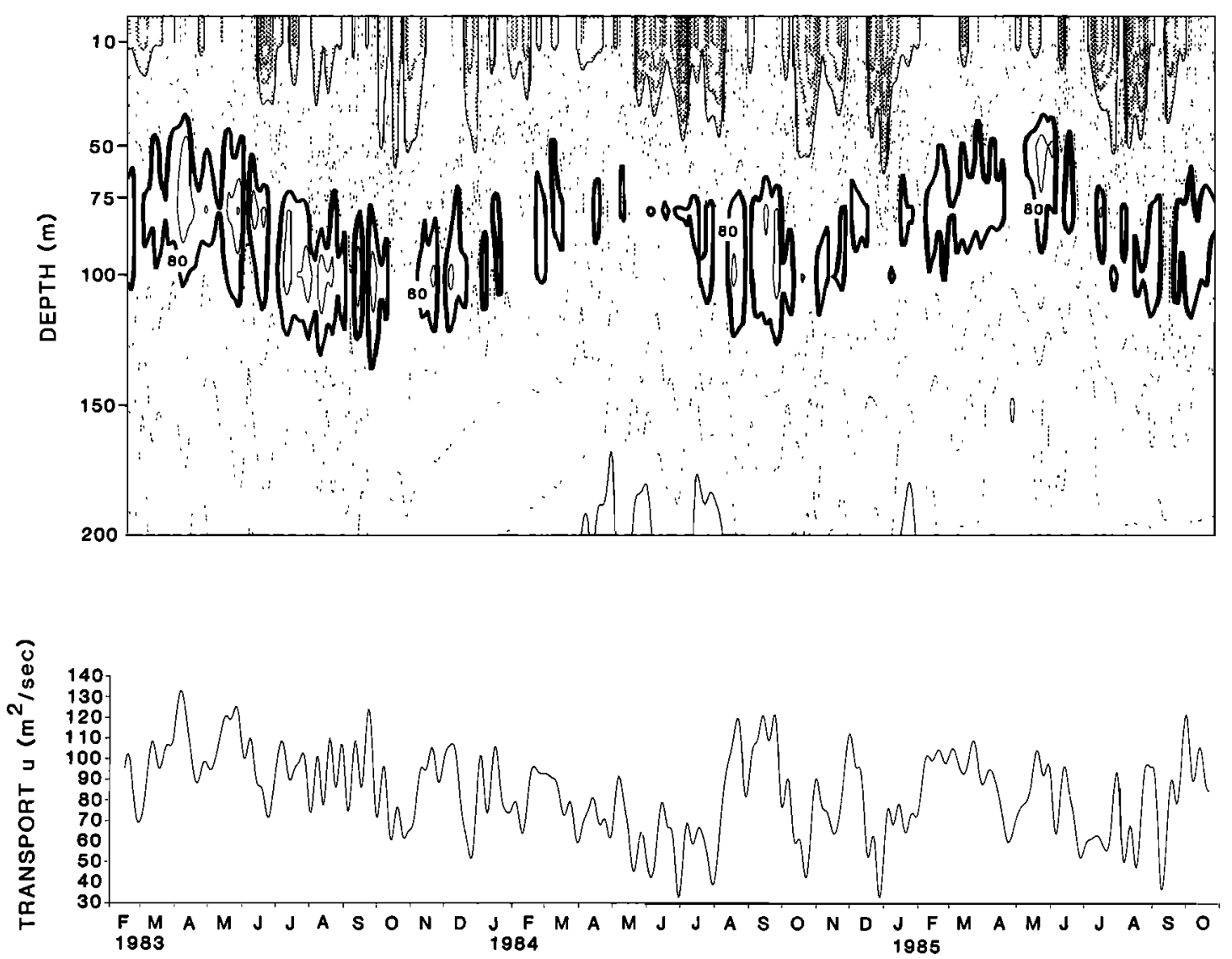

Fig. $5 b$

28W NORTH
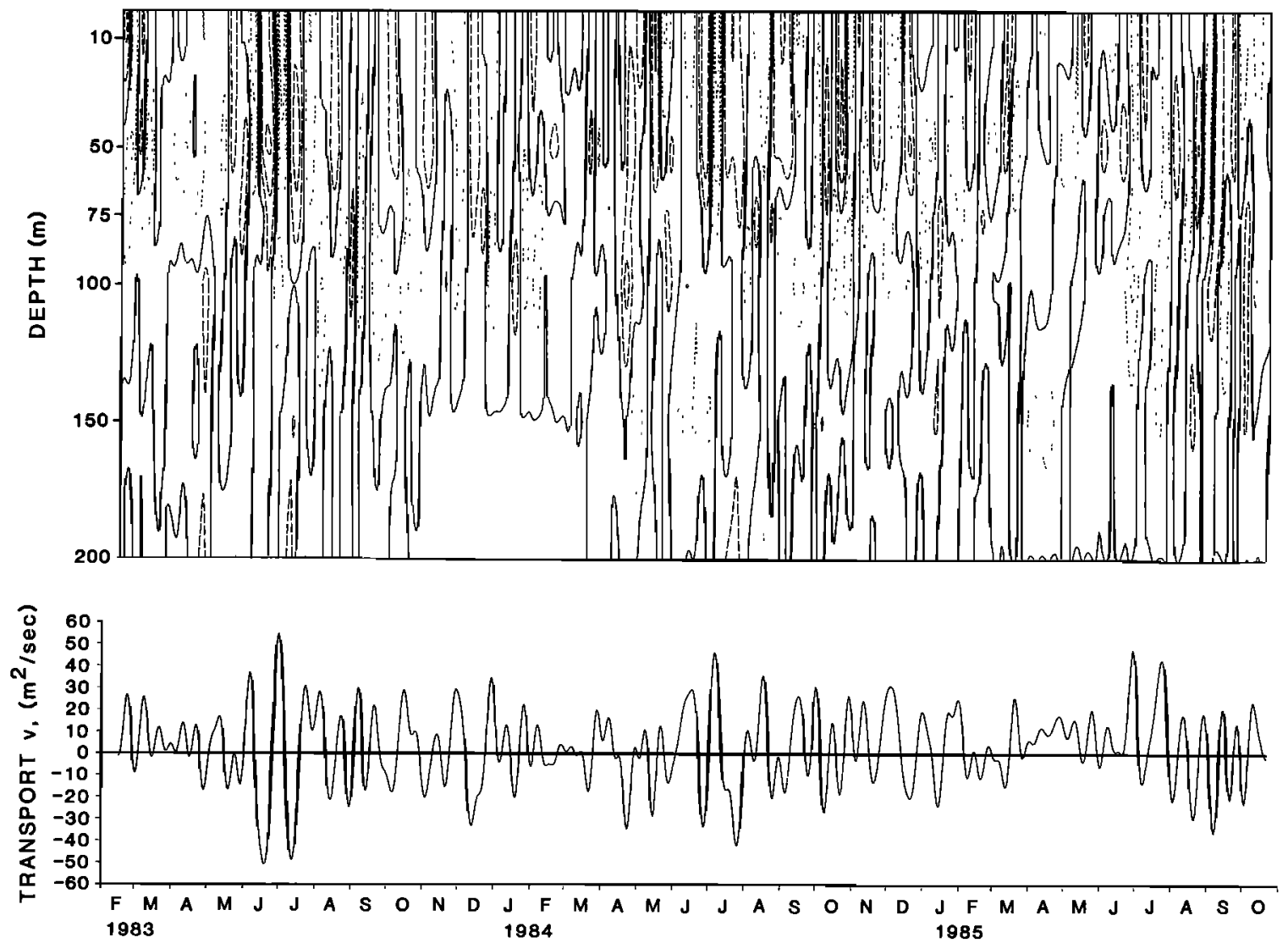

Fig. $5 c$ 


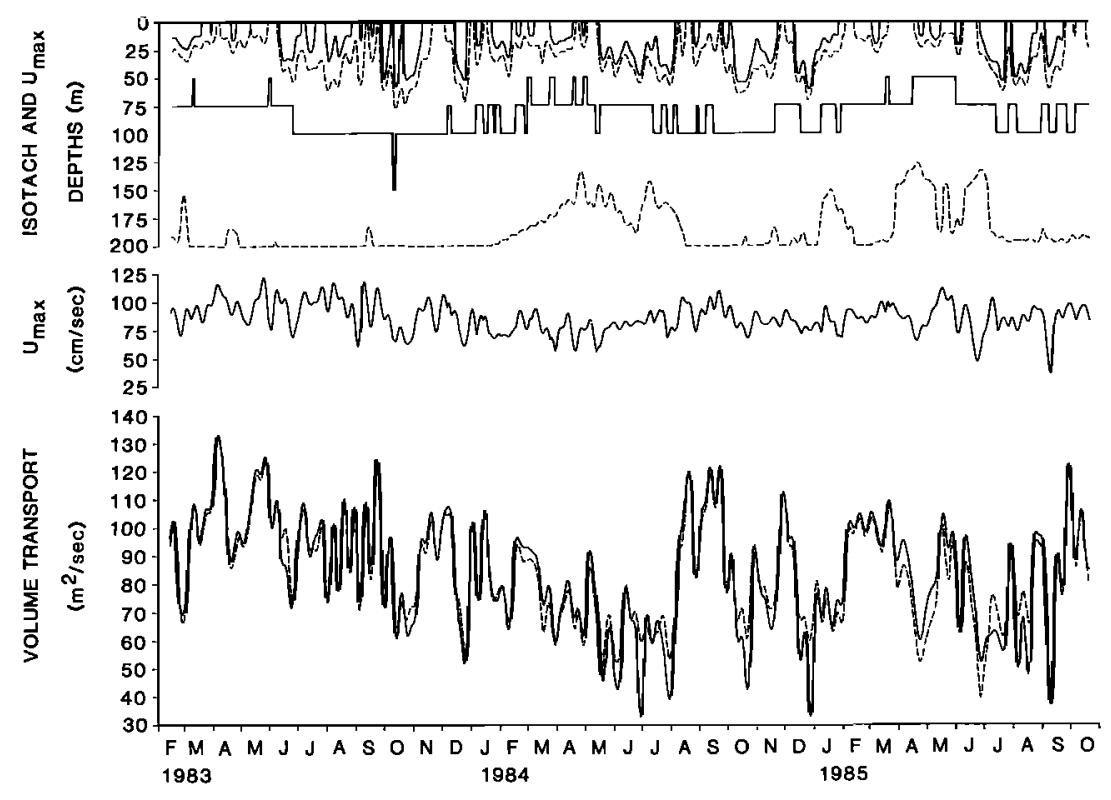

Fig. 6. Zonal current structure over the upper $200-\mathrm{m}$ of the water column based upon east component time series low-pass filtered to exclude fluctuations at time scales shorter than 10 days. (top) Depths of the 0 -cm/s (solid line) and $20-\mathrm{cm} / \mathrm{s}$ (dashed lines) isotachs computed by linear interpolation and the depth of maximum speed (solid center line). (middle) The speed observed at the depth of maximum speed. (bottom) Vertically integrated volume transport per unit width between the surface and 200-m depth (solid line), between regions of eastward flow only (dashed line), and between the eastward upper and lower $20-\mathrm{cm} / \mathrm{s}$ isotachs or $200-\mathrm{m}$ (dotted line).

the ocean tends to adjust to the large-scale wind stress variations. The wind measurements at SPP located at $01^{\circ} \mathrm{N}, 29^{\circ} \mathrm{W}$ are the only in situ open ocean time series available over the time period considered here. Comparison with other wind measurements made in 1983 and reported by Garzoli and Katz [1984] and Payne [1984] along with the historical ship report climatology of Hastenrath and Lamb [1977] suggest that the temporal variations in easterly wind stress at this station are representative of the large-scale variations over the western two thirds of the equatorial Atlantic. A primary difference between these in situ winds and the climatology, however, is that the seasonal transitions from weak to strong easterlies and conversely may occur very rapidly as opposed to a slowly varying annual harmonic as suggested by the climatological averages. The character of the ocean's response to the annual wind cycle is largely dependent upon the nature of the seasonal transitions. The rapidity with which the wind stress either intensifies or relaxes determines the growth times and subsequent interference patterns of the equatorial long waves which effect the ocean's adjustment and hence the sequence of patterns observed. This was shown in relation to the first 1.6 years of the SEQUAL moored temperature data by Weisberg and Tang $[1985,1987]$ using reduced-gravity models.

The easterly wind stress is observed to be strongest in summer and weakest in winter, with the transitions occurring in spring and fall as the intertropical convergence zone (ITCZ) shifts latitudinally. During 1983 the easterlies rapidly intensified over a month or less beginning in early April and then remained strongly developed. While not shown at the SPP station owing to a record gap, the wind record from a mooring on the equator at $24^{\circ} \mathrm{W}$ (R. Payne, personal communication, 1985) and winds inferred from inverted echo sounder (IES) ambient noise (E. J. Katz, personal communication, 1986) show that the easterly wind stress relaxation during that year was similarly rapid beginning around mid-December.
The intensification during 1984 also occurred rapidly beginning in mid-May. During both of these years, while higher frequency variations in the easterly wind stress were prominent, they were not as large as the seasonal transitions. The transitions in 1985 are not as sharply defined as those during the previous 2 years. A relaxation is observed to begin in mid-December 1984, but superimposed on it are fluctuations at time scales longer than those during the previous year. An intensification began in mid-May 1985, and while the initial buildup was rapid, the fluctuations kept the easterlies from reaching a stable level until July.

The response of the isotherms and the isotachs to these seasonal wind stress transitions are evident in Figures $5 a, 5 b$, and $5 c$. Consider the temperature in Figure $5 a$ first. Along with the seasonal intensifications, the isotherms within the thermocline undergo a sequence of upwelling followed by downwelling, with the converse occurring along with the seasonal relaxations. These sequences when combined make up the annual cycle which at this location resulted in an approximate $40-\mathrm{m}$ range for the $20^{\circ} \mathrm{C}$ isotherm. It is interesting to note the relation between the vertical position of the thermocline at this location and sea surface temperature (SST). Warmest SST occurs when the easterly wind stress is weakest, and this corresponds to the interval over which the thermocline is shoaling. Thus SST and thermocline depth generally act in opposition to each other on the equator at $28^{\circ} \mathrm{W}$. Vertically integrated temperature which is proportional to heat content, on the other hand, varies with the movement of the isotherms, so at this location vertically integrated heat content is not a good proxy for SST. The characteristic signature of upwelling followed by downwelling after the seasonal easterly wind stress intensifications replicates as a decreasing followed by increasing vertically integrated heat content signature in all 3 years centered on May 1983, June 1984, and June 1985.

The east velocity component time series of Figure $5 b$ show 
both a relationship between the vertical position of the EUC and the thermocline and a paucity of westward flow at the surface. The position of the EUC core (highlighted for speeds exceeding $80 \mathrm{~cm} / \mathrm{s}$ ) essentially follows the thermocline over its annual cycle. It is deepest after the easterlies intensify and the thermocline has adjusted downward, and it is shallowest after the easterlies relax and the thermocline has adjusted upward. While the vertical position of the EUC core undergoes a distinctive annual cycle, variations in its transport are of a more complicated nature. Westward flow at the surface associated with the SEC is also complex. Short periods of westward flow lasting for around 2 months occurred after the easterlies intensified in 1984 and 1985 but not in 1983 when the easterlies were actually stronger. However, during 1983, westward flow did develop at $0^{\circ} 75^{\prime} \mathrm{N}$ [Weisberg, 1984a]. Directly on the equator the local wind stress does not seem to be the controlling element of the surface flow, and when the surface flow is westward it rarely penetrates to 50-m depth. Previous surface moored current meter data from the central equatorial Atlantic Ocean support this finding [Weisberg, 1979, 1985].

The variations in the north component are distinctly different from either the east component or temperature as shown in the isotach plot of Figure $5 c$. While there is not evidence for an annual cycle, the higher-frequency motions (with time scales longer than 10 days here due to filtering) appear to be annually modulated and surface intensified. Examples of these behaviors are observed following the wind stress intensifications in 1983 and 1984 when energetic several-week oscillations appeared prominently in the upper $50 \mathrm{~m}$. Shear flow instability has been postulated as the causal mechanism for these oscillations [Philander, 1978], and subsequent data analyses [e.g., Weisberg, 1984b; Hansen and Paul, 1984; Philander et al., 1985] have supported this contention. The vertically integrated volume transport and the time series at $10-\mathrm{m}$ depth (Figure 1) show the annual modulation of these highfrequency north velocity component fluctuations. Minimum and maximum amplitudes appear prior to and after the easterly wind stress intensifications, respectively, and midrange amplitudes appear while the easterlies are well developed.

Variations in the vertical structure of the eastward velocity component sampled from Figure $5 b$ are shown in Figure 6. With the exception of intermittent westward flow above $50 \mathrm{~m}$, eastward speeds in excess of $20 \mathrm{~cm} / \mathrm{s}$ generally spanned the 200-m domain, with the depths of maximum speed observed between $50 \mathrm{~m}$ and $100 \mathrm{~m}$. The speed sampled at the depth of maximum speed (the EUC core) has a mean and an rms deviation about the mean of $86 \pm 13 \mathrm{~cm} / \mathrm{s}$ with no discernable annual cycle. The volume transport per unit width does not show an annual cycle either, nor does it show a consistent relationship with the thermocline variations or the events in wind stress from year to year. This is not a consequence of the choice of integration interval over the upper $200 \mathrm{~m}$, since all three curves are nearly the same. The only wind stress events that do leave their mark on the thermocline and EUC transport in all 3 years are the short-lived relaxation events immediately preceding the seasonal intensifications (see April 1983, May 1984, and May 1985). During these periods, peaks are observed in both vertically integrated heat content and EUC transport; however, there is nothing outstanding about these peaks: they are not statistically coherent, and had there not been a reason to single them out, i.e., known wind events, they would have no grounds for mention. It is surprising that while these events do have replicating signatures in the verti- cal integrals, the major seasonal transitions in easterly wind stress do not. For example, the period May-June 1983 after the winds intensified shows a relative transport maximum, while the same period in 1984 shows a relative minimum. Similar differences between these 2 years are observed following the wintertime wind stress relaxations.

\section{Empirical Orthogonal Function Analyses}

To investigate the vertical structure of the low-frequency velocity component and temperature fluctuations and how they integrate to give volume transport and heat content, respectively, the low pass-filtered time series of section 3 were analyzed using time domain empirical orthogonal functions (EOFs) [e.g., Wallace and Dickinson, 1972]. EOFs were calculated separately for the velocity component and temperature time series by solving for the eigenvalues and eigenvectors of their respective covariance matrices. This results in sets of orthogonal modes upon which the data may be projected to obtain the time dependence of each particular mode. These modes when summed yield the original low pass-filtered time series at each depth. The matrix formulation used is as follows:

$$
\begin{gathered}
D=E H \\
\lambda=E E^{\prime} \\
n I=H H^{\prime}
\end{gathered}
$$

where $D, E$, and $H$ are the data (minus their mean values), the eigenvector, and the modal time dependence matrices, respectively; $\lambda$ is the matrix of eigenvalues and is the time series record length; $I$ is the identity matrix; and the prime denotes the transpose. In this formulation the units are contained in the eigenvectors, while the modal projection time series are orthonormal.

Table 3 lists the variance in each of the first three EOF modes for the velocity components and temperature and the percentages of total variance that they account for. Figure 7 shows the corresponding eigenvectors and Figure 8 shows the corresponding modal projection time series. In terms of variance distribution amongst modes, the vertical structure of the temperature time series appears to be simpler than that for the velocity components, with $77 \%$ of the variance in the first mode for temperature compared with $53 \%$ of the variance in the first mode for either the east or the north components. From the temperature eigenvectors it is observed that the first mode has a maximum within the thermocline, and its modal projection time series resembles the isotherm behavior within the thermocline and the vertically integrated heat content. The

TABLE 3. Variance and Percent of Variance Accounted for by the First Three EOF Modes Calculated for the Low Pass-Filtered $u$ and $v$ Velocity Components and Temperature Data of Figures $5 a, 5 b$, and $5 c$

\begin{tabular}{lcccccc}
\hline & \multicolumn{3}{c}{$u$} & & \multicolumn{2}{c}{$T$} \\
\cline { 2 - 6 } \cline { 5 - 7 } Mode & $\begin{array}{c}\text { Variance, } \\
\mathrm{cm}^{2} / \mathrm{s}^{2}\end{array}$ & Percent & $\begin{array}{c}\text { Variance, } \\
\mathrm{cm}^{2} / \mathrm{s}^{2}\end{array}$ & Percent & $\begin{array}{c}\text { Variance, } \\
\left({ }^{\circ} \mathrm{C}\right)^{2}\end{array}$ & Percent \\
\hline 1 & $1.23 \times 10^{3}$ & 53 & $7.89 \times 10^{2}$ & 53 & 9.49 & 77 \\
2 & $5.07 \times 10^{2}$ & 22 & $2.90 \times 10^{2}$ & 20 & 1.57 & 13 \\
3 & $3.35 \times 10^{2}$ & 15 & $1.79 \times 10^{2}$ & 12 & 0.80 & 7 \\
Sum & & 90 & & 85 & & 97 \\
\hline
\end{tabular}



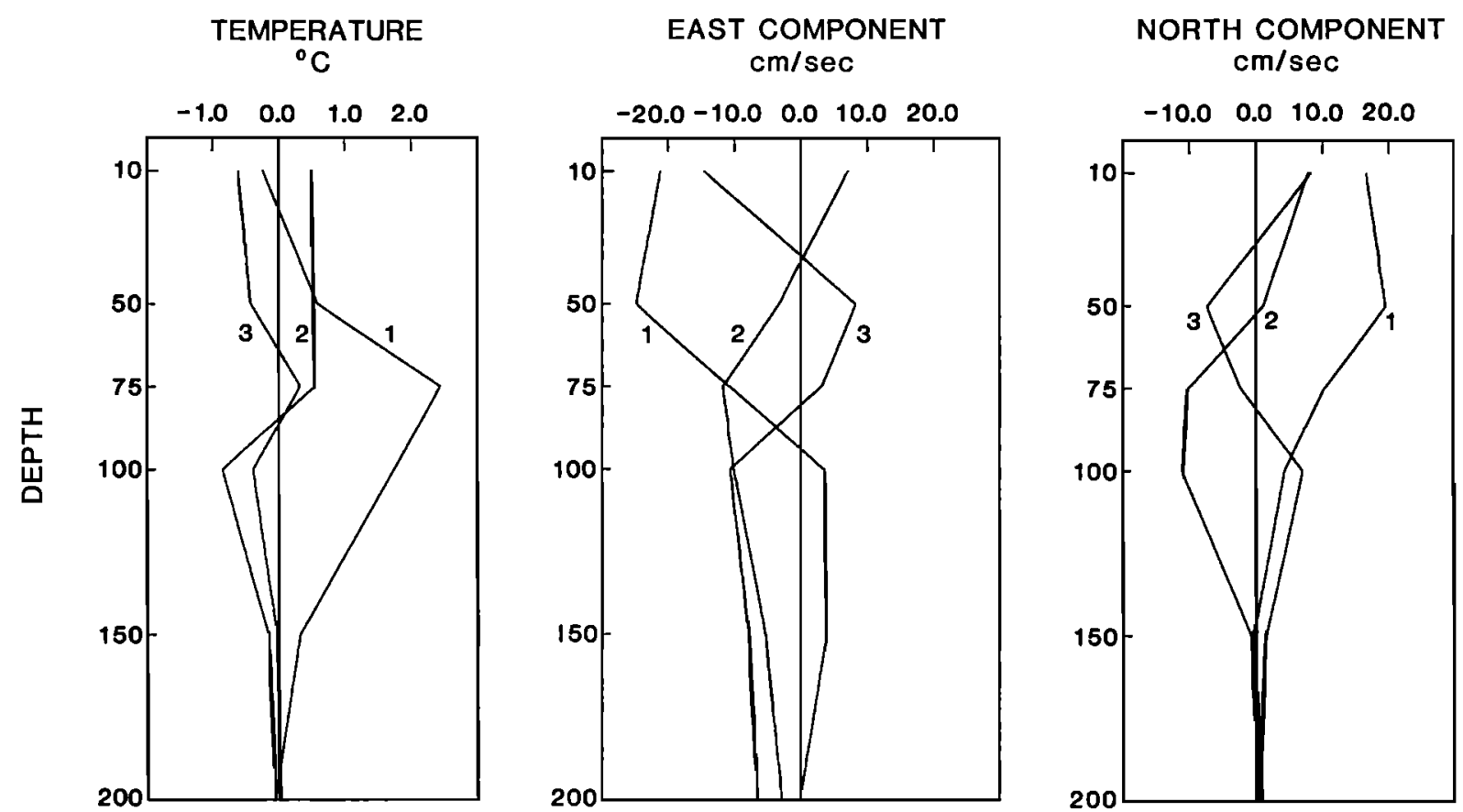

Fig. 7. Eigenvectors for the first three EOF modes computed for temperature and for the east and north velocity components using time series low-pass filtered to exclude fluctuations at time scales shorter than 10 days.

second- and third-mode eigenvectors are in phase at $75 \mathrm{~m}$ and below, and they reverse sign across the thermocline. Therefore they largely cancel each other out in the vertical integral. On the other hand, they are out of phase near the surface, thereby accounting for the different behavior noted in section 3 between the temperature variations within the thermocline and SST.

The east velocity component EOFs appear distinctly different from those of temperature both in the eigenvectors and in their modal projection time series. It is the second-modal projection in the east component that most closely resembles the first-model projection in temperature. However, the secondmode east component eigenvector reverses sign across the EUC. Therefore it represents the vertical excursions of the EUC isotach depths along with the thermocline as shown in Figure 5 as opposed to representing an annual cycle in EUC speed or transport. The first-modal eigenvector is largest at 10 $\mathrm{m}$ and $50 \mathrm{~m}$, and its modal projection time series most closely resembles the fluctuations observed at those depths. Thus the near-surface currents are responsible for a large part of the total transport variations.

The north component EOFs also appear unique from either the east component or temperature. The first-mode eigenvector and modal projection time series show the surface intensification and annual modulation discussed earlier, respectively.

How well do the EOFs represent the vertically integrated heat content and volume transport? Figure 9 shows the vertical integrals for temperature and the velocity components calculated directly from the low pass-filtered data and from sums over the EOF modes. Four time series are given for each component: the data, the means plus the first mode, the means plus the first two modes, and the means plus the first three modes. For both temperature and the north component, the mean plus the first mode accounts very well for the vertically integrated heat content and volume transport, respectively.
Contributions from the higher modes cancel out over the water column. The east component transport is not so easily accounted for. While the first mode (near surface currents) accounts for part of the transport variations, it takes all of the first three modes to track the data.

\section{Higher-FrequenCy VARIABILITY}

The velocity component and temperature data contain fluctuations over a broad range of frequencies. Given 2.7 years of continuous data, allowing for relatively high resolution in the frequency domain while maintaining enough degrees of freedom for statistical inference, the purpose of the present section is to investigate whether or not specific narrow-band processes exist in the upper equatorial ocean. If so, they may appear as coherent peaks in the cross spectra between the horizontal velocity components and between these velocity components and temperature. Such a finding would imply that the ocean responds in a resonant manner to external forcing or that the forcing itsell is narrow band.

Three measures of coherency and phase were calculated using the data of Figure 1. These consisted of the coherence squared between the north and east velocity components with temperature and between the anticlockwise and clockwise rotary components of velocity (ellipse stability). The velocity component and temperature coherence squared and phase are shown in Figure 10, and the ellipse stability and orientation (the phase between the clockwise and anticlockwise rotary components) are shown in Figure 11 for frequencies lower than $0.025 \mathrm{cph}$. Phase is given in radians, and orientation is given as a fraction of $\pi$ radians. Averaging in the frequency domain was performed over five adjacent bands on each side of the central band for a total bandwidth of $0.000458 \mathrm{cph}$ corresponding to approximately 21 degrees of freedom. A uniform averaging window was convolved across the spectra, so 


\section{a. TEMPERATURE}
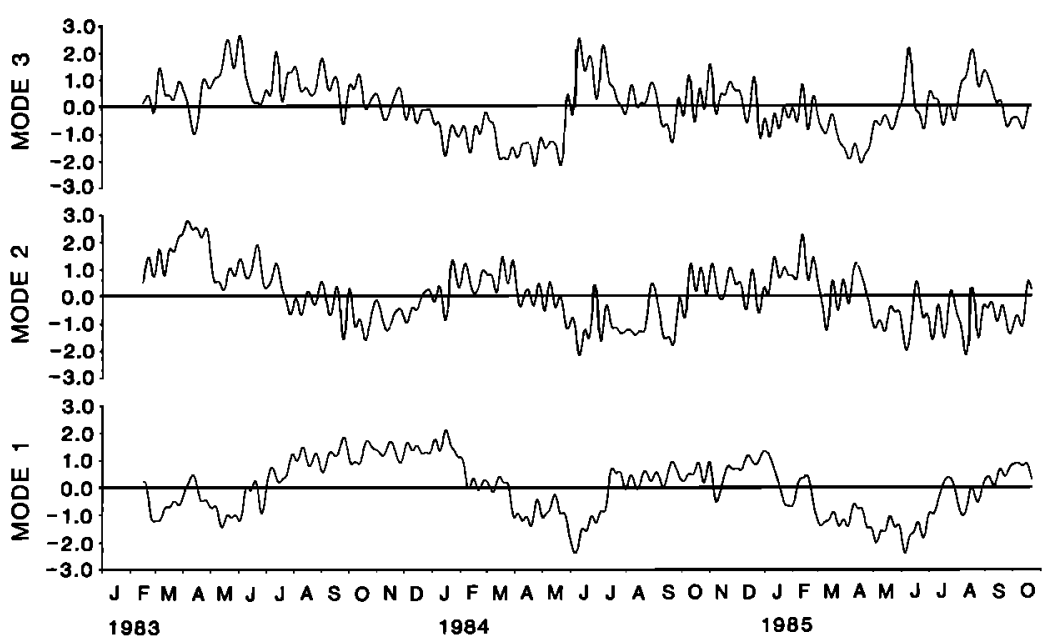

\section{b. EAST COMPONENT}
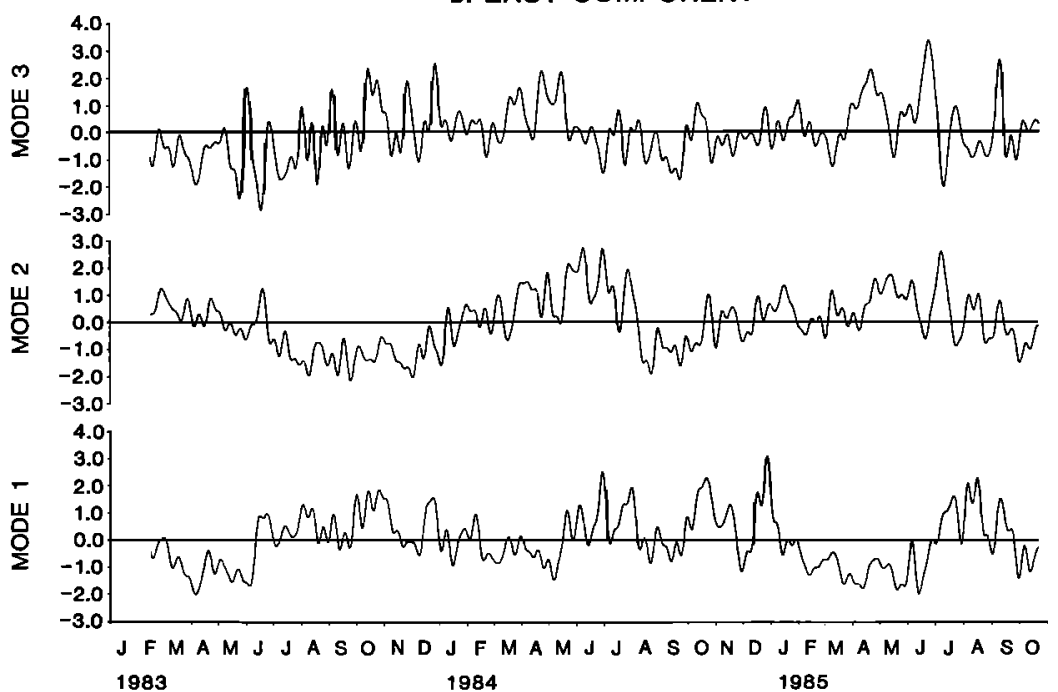

\section{c. NORTH COMPONENT}
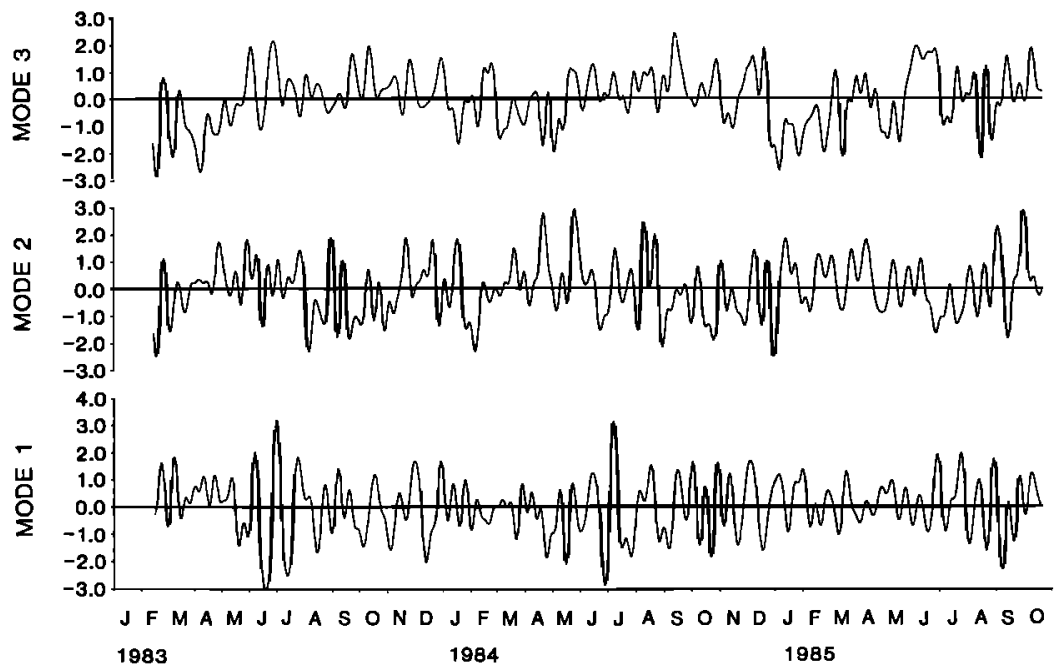

Fig. 8. Modal projection time series for the EOF modes of Figure 7: (a) temperature, (b) east component, and (c) north component. 


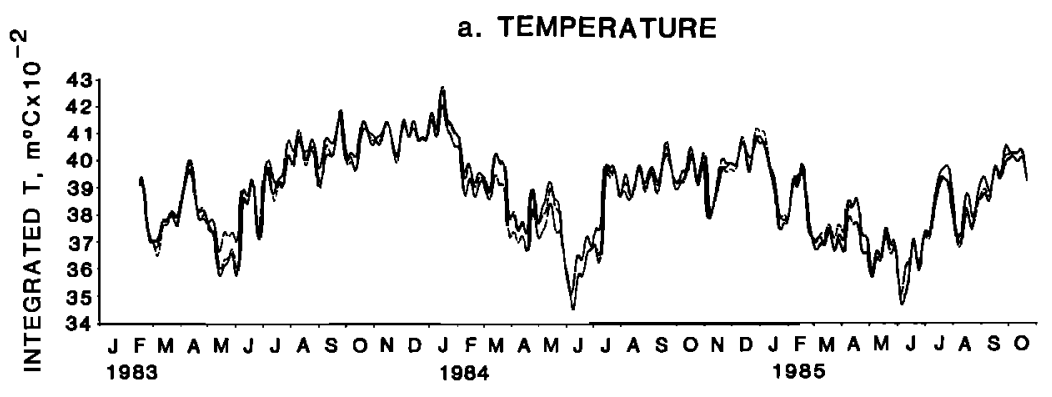

b. EAST COMPONENT

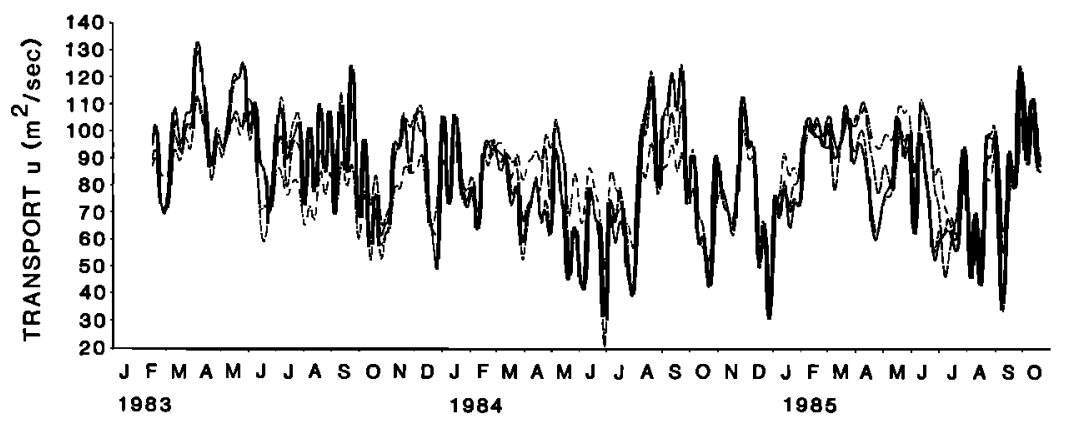

c. NORTH COMPONENT

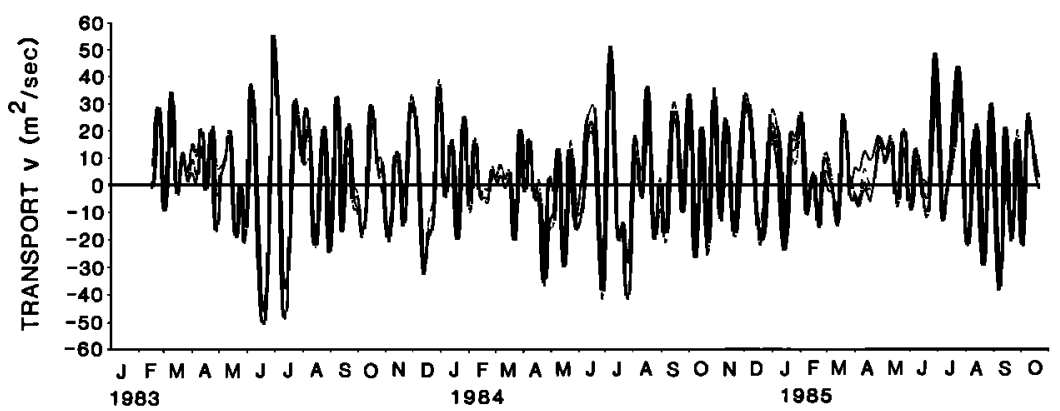

Fig. 9. Comparisons between vertically integrated temperature or volume transport per unit width and EOF mode sums: (a) temperature, (b) east component, and $(c)$ north component. The solid lines are the vertical integrals from the data, the dotted-dashed lines are the means plus the first mode, the dashed lines are the means plus the first two modes, and the dotted lines are the means plus the first three modes.

data points in these figures must be separated by the indicated bandwidth in order to be independent. The $90 \%$ significance level for the null hypothesis on coherence squared is indicated by horizontal lines.

Consider the east component and temperature coherence first. At 10-m depth, several peaks, each approximately one averaging bandwidth wide, appear above the significance level, with the phase being plus or minus $\pi$ radians. At $50-\mathrm{m}$ depth the coherence intensity increases, and the phase remains the same. Coherence vanishes at $75-\mathrm{m}$ depth. At $100-\mathrm{m}$ depth the coherence again increases in narrow peaks, and the phase is zero. Maximum broadband coherence with zero phase is observed at $150-\mathrm{m}$ depth. At $200-\mathrm{m}$ depth, while the phase remains zero, the coherence falls off. Unlike the east component, the north component and temperature are observed to be generally incoherent at all depths sampled, with a possible excep- tion near the low-frequency end (time scales around a month) where instability waves may be a factor.

That (1) the east component and temperature coherence is maximum where the east component vertical shear is largest $(50 \mathrm{~m}$ and $150 \mathrm{~m}),(2)$ the east component and temperature coherence is minimum where the shear is smallest $(75 \mathrm{~m})$, and (3) the phase switches from out of phase to in phase as the shear reverses sign across the EUC core all suggest that the east component-temperature coherence arises owing to vertical advection of eastward momentum by vertical velocity fluctuations as opposed to advection of temperature by horizontal velocity fluctuations. This is further supported by the general absence of north component-temperature coherence. At least kinematically, the linearized terms including the mean vertical shear in the horizontal momentum equations would seem to be important over a large portion of the spectrum for time 

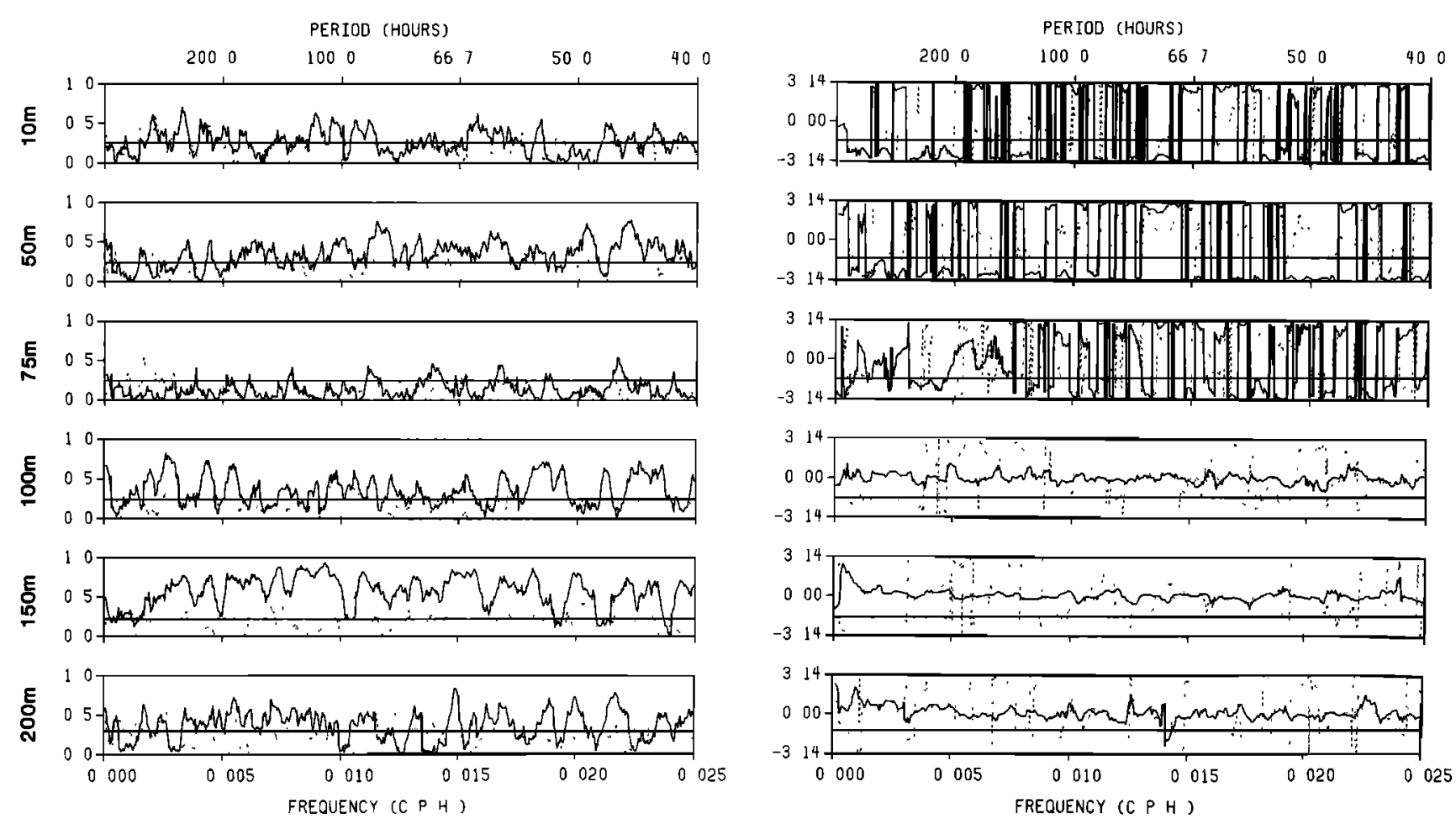

Fig. 10. Velocity component and temperature coherence squared and phase as functions of frequency computed over the 2.7 years of data with the indicated bandwidth. Solid and dashed lines represent the east component with temperature and the north component with temperature, respectively. The $90 \%$ significance level for the null hypothesis with a nominal 21 degrees of freedom (less for the $150-\mathrm{m}$ and $200-\mathrm{m}$ depths) is given by horizontal lines.

scales containing the instability waves and shorter time scales. Similar findings from previous shorter-duration measurements were given by $W$ eisberg [1985].

The ellipse stability is observed to be generally below significance level with few exceptions above 150-m depth, while
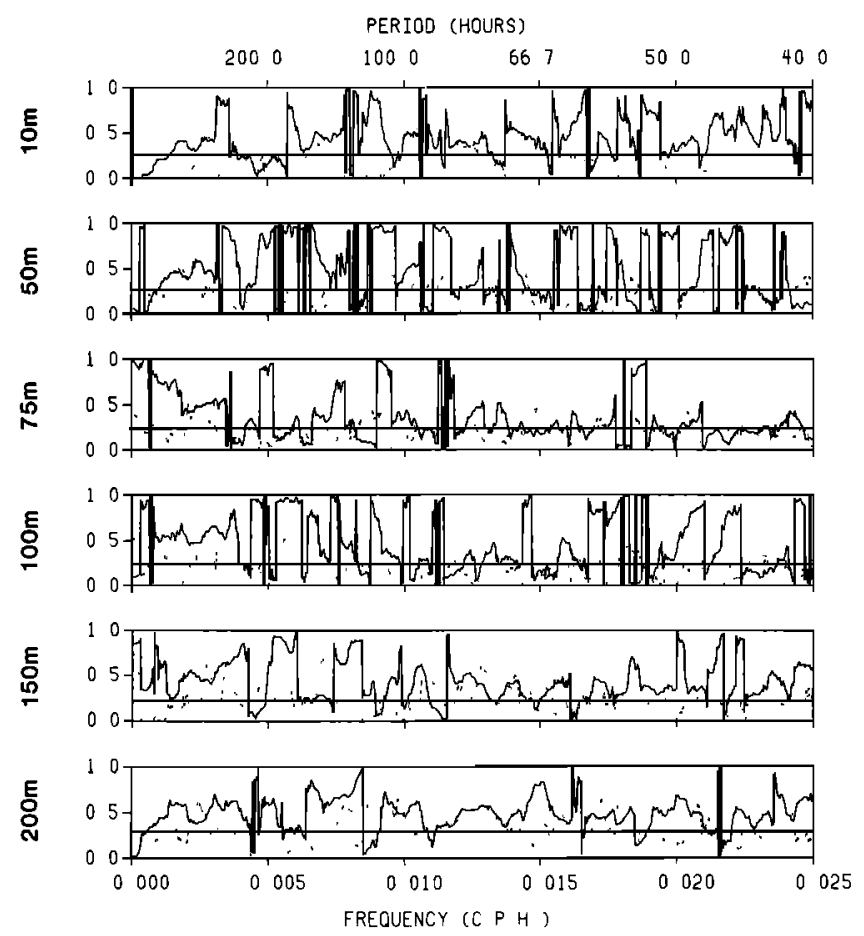

Fig. 11. Ellipse stability (dashed lınes) and orientation (solid lines) computed as in Figure 10. Units for orientation are in fractions of $\pi$ radians measured anticlock wise from east. some coherence appears at 200-m depth. Where narrow peaks to extend above the significance level there does not appear to be any consistency from one depth to another. Organized motion occurring regularly over the 2.7 years of record does not seem to be the case. While this is a negative result, it may have some importance, since several past studies have searched for resonant equatorial inertia-gravity wave motions. If resonant modes do exist, they are not readily apparent from the analyses given here, with one reason being that the strong background currents may obscure their presence in upper ocean current meter data. For example, the east component fluctuations derive in part from vertical shear. Another possibility, of course, is that narrow band resonant modes do not exist. In this regard, joint analyses between the SEQUAL wind time series and the moored data along with a search for shorter duration coherent segments may be enlightening and will be a subject of future work.

\section{Discussion}

The EUC in the Atlantic Ocean has been studied numerous times over the past three decades, primarily by shipboard profiling systems. Katz et al. [1981] discusses these findings and attempts to describe the annual cycle of the EUC by composing the various shipboard measurements obtained during the Global Weather Experiment in 1979. From 22 samples obtained between $25^{\circ} \mathrm{W}$ and $33^{\circ} \mathrm{W}$ they surmised that a season of high transport exists around March and a season of low transport exits around June-July, with transport variations ranging by a factor of 2 about the annual mean value. Highest values of transport during springtime were attributed to eastward surface flow, the occurrence of which has a historical basis. Lowest values of transport during summer were 
supported by measurements made during the GARP Atlantic Tropical Experiment in 1974.

The SEQUAL moored current meter data now provide continuous measurements over the annual cycle. One new observation presented here is that the core of the EUC tracks the thermocline vertically through its annual cycle, confirming a similar numerical model result of Philander and Pacanowski [1986]. This explains the large annual variations in eastward current speed at a given depth within the thermocline reported previously by Weisberg [1985] and again observed here. The speed at the EUC core depth and the transport on the other hand are more complicated. Figure 6 did not show a distinctive annual cycle in speed or transport, and while the isotherm and isotach depth variations replicate over three annual cycles, features within the transport or speed records generally did not. Minimum transport was observed in June-July 1984 and perhaps again in 1985, when the surface currents were westward, but not in 1983, when a westward surface flow failed to establish on the equator. During 1984, maximum transport values occurred in late summer immediately following the minimum. The EOF analyses of section 4 showed that roughly half of the transport variations were due to the first mode, which most closely resembled the near surface current variations, so at least in regard to the June-July minimum and the importance of the surface currents, there is some support here for the results of Katz et al. [1981]. Further discussion on transport or attempts to relate it to models or the zonal pressure gradient will be deferred until additional SEQUAL and FOCAL data on this subject have been synthesized.

Unlike the variability in vertical position and transport of the EUC, the eastward component of velocity at its core was relatively constant. It showed a rms deviation of $13 \mathrm{~cm} / \mathrm{s}$ about an $86 \mathrm{~cm} / \mathrm{s}$ mean value when averaged over 2.7 years and was even smaller during 1984 and 1985. Fofonoff and Montgomery [1955] were the first to suggest that meridional advection of vorticity in the presence of an eastward zonal pressure gradient force could account for the EUC. Cane [1980] expanded upon this idea by arguing that the speed of the EUC should be independent of the pressure gradient magnitude since it sets just the rate at which fluid converges on the equator and not the conversion of vorticity from planetary to relative. Our finding of relatively constant core speed supports this fundamental nonlinear EUC theory.

Before concluding that the EUC core speed is observed to be independent of pressure gradient magnitude, however, we point out that the annual pressure gradient variations at the depth of the EUC core are considerably smaller than those inferred from surface dynamic topography alone. Weisberg and Weingartner [1986] showed that the isopycnal slopes, when integrated downward from the surface, buffer the pressure gradient variations at the depth of the EUC.

\section{Summary}

A description of temperature and currents over the upper $200 \mathrm{~m}$ at $0^{\circ}, 28^{\circ} \mathrm{W}$ has been presented based upon 2.7 years of surface moored current meter data obtained in conjunction with the Seasonal Response of the Equatorial Atlantic Experiment. These data are a subset of a larger but shorter duration array. The thermocline evolved over a distinct annual cycle in response to the surface easterly wind stress and the vertical position of the Equatorial Undercurrent core tracked the thermocline. This combined cycle replicated over the 3 years of record. Speed at the EUC core was relatively constant over the annual cycle in support of fundamental nonlinear EUC theory. EUC transport variations, however, were more complicated and were related in part to near-surface current variations. Higher-frequency north velocity component oscillations appeared to be annually modulated.

When averaged over 2.7 years, the north component mean values at this location were not statistically different from zero. The east velocity component means were comparable with previous EUC profiles. Directly on the equator the South Equatorial Current was rarely established at $10-\mathrm{m}$ depth. It developed for short duration immediately upon the seasonal intensification of easterly wind stress in springtime but was highly variable, and it abruptly halted in the wake of accompanying instability waves in spite of continued and strong easterly wind stress. This finding is supported by previous surface moored current meter data sets from the equatorial Atlantic Ocean. Locally, the surface wind stress does not appear to be the controlling element for the surface currents on the equator in the central Atlantic.

A preliminary analysis of the velocity component and temperature coherences suggested that vertical advection of eastward momentum in the presence of large mean shear contributes to the higher-frequency east component fluctuations. Ellipse stability was also generally below significance level over the broad band of frequencies associated with equatorially trapped inertia-gravity waves.

Acknowledgments. Support was provided by the Oceanography Section, National Science Foundation, under grants OCE-8311848 and OCE-8515869. S. Garzoli kindly provided wind data prior to publication for inclusion herein. Moorng deployments were accomplished with the enthusiastic officer and crew support of the R/Vs Conrad, Endeavor, Gyre, and Knorr. The Technical Services Group for the University of Rhode Island, Graduate School of Oceanography, provided most of the current meters with assistance from the Woods Hole Oceanographic Institution Buoy Group. Mooring design and experience gained with such moorings in the equatorial Pacific Ocean was kindly shared by $D$. Halpern. Our mooring technician, P. Blankınship, was a major factor in the success of the program.

\section{REFERENCES}

Cane, M., On the dynamics of equatorial currents, with application to the Indian Ocean, Deep Sea Res., 27, 525-544, 1980.

Cane, M., and E. S. Sarachik, Forced baroclinic ocean motions, I, The linear equatorial unbounded case, J. Mar. Res., 34, 629-665, 1976.

Cane, M. and E. S. Sarachik, Forced baroclinic ocean motions, II, The linear equatorial bounded case, J. Mar. Res., 35, 395-432, 1977

Fofonoff, N. P., and R. B. Montgomery, The equatorial undercurrent in the light of the vorticity equation, Tellus, 8, 518-521, 1955.

Garzoli, S., and E. J. Katz, Winds at St. Peter and Paul rocks during the first SEQUAL year, Geophys. Res. Lett., $1 /, 715-718,1984$.

Halpern, D., Comparison of upper ocean VACM and VMCM observations in the equatorial Pacific, J. Atmos. Oceanic Technol., in press, 1987.

Halpern, D., R. Weller, M. Briscoe, R. Davis, and J. McCullough, Intercomparison tests of moored current measurements in the upper ocean, J. Geophys. Res., 86, 491-528, 1981.

Hansen, D. V., and C. A. Paul, Genesis and effects of long waves in the equatorial Pacific, J. Geophys. Res., 89, 10,431-10,440, 1984.

Hastenrath, S., and P. J. Lamb, Climatic Atlas of the Tropical Atlantic and Eastern Pacific Ocean, 25 pp., 9 charts, University of Wisconsin Press, Madison, 1977.

Katz, E. J., R. L. Molinari, D. E. Cartwright, P. Hisard, H. U. Lass, and A. deMesquita, The seasonal transport of the Equatorial Undercurrent in the western Atlantic (during the Global Weather Experiment), Oceanol. Acta, 4, 445-450, 1981. 
Moore, D. W., and S. G. H. Philander, Modelling of the tropical ocean circulation, in The Sea, vol. 6, edited by E. Goldberg et al., pp. 319-361, Interscience, New York, 1977.

Papoulis, A., Probability, Random Variables, and Stochastic Processes, 583 pp., McGraw Hill, New York, 1965.

Payne, R., Surface wind measurements in SEQUAL I, Geophys. Res. Lett., 11, 719-721, 1984.

Philander, S. G. H., Instabilities of equatorial currents, 2, J. Geophys. Res., 83, 3679-3682, 1978.

Philander, S. G. H., and R. C. Pacanowski, A model of the seasonal cycle in the tropical Atlantic Ocean, J. Geophys. Res., 9I(C12), 14,192-14,206, 1986.

Philander, G., D. Halpern, D. Hansen, R. Legeckis, L. Miller, C. Paul, R. Watts, R. Weisberg, and $M$. Wimbush, Long waves in the equatorial Pacific Ocean, Eos Trans. AGU, 66, 154-156, 1985.

Wallace, J. M., and R. E. Dickinson, Empirical orthogonal representation of time series in the frequency domain, I, Theoretical considerations, J. Appl. Meteorol., $11,887-900,1972$.

Weisberg, R. H., Equatorial waves during GATE and their relation to the mean zonal circulations, Deep Sea Res., 26, suppl. II, 179-198, 1979.

Weisberg, R. H., Seasonal adjustments in the equatorial Atlantic during 1983 as seen by surface moorings, Geophys. Res. Lett., 11, $732-735,1984 a$.

Weisberg, R. H., Instability waves observed on the equator in the Atlantic Ocean during 1983, Geophys. Res. Lett., 11, 753-756, $1984 b$.
Wersberg, R. H., Equatorial Atlantic velocity and temperature observations: February-November 1981, J. Phys. Oceanogr., 15, 533$543,1985$.

Weisberg, R. H. and A. M. Horigan, Low frequency variability in the equatorial Atlantic, J. Phys. Oceanogr., II, 913-920, 1981.

Weisberg, R. H., and T. Y. Tang, On the response of the equatorial thermocline in the Atlantic Ocean to the seasonally varying tradewinds, J. Geophys. Res., 90, 7117-7128, 1985.

Weisberg, R. H., and T. Y. Tang, Further studies on the response of the equatorial thermocline in the Atlantic Ocean to the seasonally varying tradewinds, J. Geophys. Res., in press, 1987.

Weisberg, R. H. and T. J. Weingartner, On the baroclinic adjustment of the zonal pressure gradient in the equatorial Atlantic Ocean, $J$. Geophys. Res., 91, 11,717-11,725, 1986.

Weller, R., and R. E. Davis, A vector measuring current meter, Deep Sea Res., 27, 565-582, 1980.

J. H. Hickman, T. Y. Tang, T. J. Weingartner, and R. H. Weisberg, Department of Marine Science, University of South Florida, 140 Seventh Avenue, South Saint Petersburg, FL 33701.

(Received September 3, 1986; revised January 6,1987 ; accepted January $6,1987$. 